\section{Avaliação do perfil auditivo de militares de um quartel do Exército Brasileiro}

\section{Audiometric assessment for military personnel}

Ana P. Silva ${ }^{1}$, Everardo A. da Costa ${ }^{2}$, Salete M. M. Rodrigues $^{3}$, Humberto L. R. Souzat, Valéria G. Massaferas

\section{Resumo / Summary}

\section{$\mathbf{N}$} o serviço militar, os sujeitos estão expostos a ruídos contínuos em oficinas e a ruídos de impacto provenientes de armas de fogo e detonações. Estes ruídos indesejáveis são capazes de causar lesão ao sistema auditivo, muitas vezes irreversível, além de outros efeitos em todo o organismo. Objetivo: Avaliar os perfis auditivos de um grupo de militares e, em face dos resultados, incentivar a implementação de medidas preventivas para perdas auditivas, como programa de conservação auditiva. Forma de estudo: Coorte transversal. Material e Método: Avaliação auditiva de 97 sujeitos que trabalham em uma organização militar do Exército, por meio de entrevista, otoscopia e exames audiométricos. Resultados: 38,1\% dos militares examinados apresentaram alterações audiométricas supostamente induzidas por ruído, predominantemente nos artilheiros, com predomínio da perda auditiva unilateral. $64,5 \%$ dos militares examinados não utilizava proteção adequada. Conclusão: A grande ocorrência da perda auditiva entre os militares e a falta de proteção adequada à exposição ao ruído indica a necessidade de se implantarem, nesta categoria, medidas de prevenção de perda auditiva.

\author{
Palavras-chave: trauma acústico, perda auditiva \\ induzida por ruído, militares, arma de fogo. \\ Key words: acoustic trauma, noise-induced \\ hearing loss, military, firearms.
}

T he individuals rendering the military service are often liable to frequent noise in factories and discharge sounds deriving from firearms and detonations. These sort of undesirable sounds cause lesions the auditory system, which are sometimes irreversible, besides provoking bad effects to the body as a whole. Aim: Evaluating the auditory profiles from a specific group of military personnel, and according to the achieved results to promote the incentive towards the implantation of preventive measures related to auditory losses, such as auditory preservation programs. Study design: Transversal cohort. Material and Method: Auditory evaluation of 97 individuals working in a military organization, which included interviews, as well as otoscopic and audiometric tests. Results: From the total examined personnel, 38,1\% presented audiometric changes supposedly noise-induced since these changes prevailed in the artillerymen, being the unilateral hearing loss predominant. The use of no proper protection equipment was observed in $64,5 \%$ of the total examined military personnel. Conclusion: The high level of hearing loss occurrences found between the military personnel joined to the absence of proper protection equipment for the exposition to noises, indicate the need of implanting prevention measures to avoid hearing losses among theses professionals.

\footnotetext{
${ }^{1}$ Otorrinolaringologista, estagiária do Ambulatório de Otorrinolaringologia Ocupacional e aluna especial de pós-graduação em Saúde Coletiva, FCM, Unicamp.

${ }^{2}$ Professor Doutor Colaborador da Disciplina de Otorrinolaringologia, Cabeça e Pescoço e do Programa de Pós-Graduação em Saúde Coletiva, FCM, Unicamp. ${ }^{3}$ Professora Adjunta do Departamento de Otorrinolaringologia do Hospital das Clinicas da Faculdade de Medicina de Pouso Alegre/ MG.

${ }^{4}$ Médico Militar, $1{ }^{\circ}$ Tenente do Grupo Artilharia de Campanha do Exército Brasileiro. ${ }^{5}$ Fonoaudióloga.

Endereço para correspondência: Ana Paula da Silva - Rua Duque de Caxias, 957 Centro Santa Bárbara d' Oeste SP 13450-000 Tel (0xx19) 3463-6073 - Fax: (0xx19) 3455-0101 - E-mail: anasbo@bol.com.br

Trabalho apresentado no $3^{\circ}$ Congresso Triológico de Otorrinolaringologia no Rio de Janeiro/RJ, no período de 8 a 11 de outubro de 2003 Instituição: Disciplina de Otorrinolaringologia, Cabeça e Pescoço da Faculdade de Ciências Médicas da Unicamp/SP. Artigo recebido em 04 de abril de 2004. Artigo aceito em 11 de maio de 2004.
} 


\section{INTRODUÇ̃̃O}

Os ruídos de impulso de alta intensidade causados pelas explosões são a causa de procura médica mais freqüente em militares nos Estados Unidos, bem como em outros paises ${ }^{1}$. No Brasil, os estudos epidemiológicos de distúrbios auditivos causados por ruídos de impulso de alta intensidade em militares são escassos.

Uma porcentagem considerável da população industrializada sofre de problemas auditivos, sendo os ruídos de impulso de alta intensidade responsáveis por uma quantidade significativa de perda auditiva permanente ${ }^{2}$.

Entende-se por ruído de impacto ou de impulso aquele que apresenta picos de energia acústica de duração inferior a 1 (um) segundo, a intervalos superiores a 1 (um) segundo ${ }^{3}$. Os ruídos de impacto podem ser classificados em simples e repetitivos. Os ruídos de impacto simples são aqueles desencadeados pelo manuseio de materiais, marteladas e também disparos de arma de fogo; já os ruídos de impacto repetitivos são aqueles produzidos por prensas automáticas, guilhotinas ou ferramentas pneumáticas, os disparos de arma de fogo em rajadas consecutivas ou mesmos disparos repetidos ${ }^{4}$. (NR15)

Segundo Plontke et al. ${ }^{2}$, o ruído de impacto pode ser definido como sinais sonoros curtos com duração ao redor de 0,2 ms que são usualmente produzidos por rápidas expansões de gás, como armas de fogo e explosões de bombas. Estes sons podem atingir intensidades e freqüências ao redor de 140dB NPS em 2 e $3 \mathrm{kHz}$, respectivamente e podem, por essa razão, ser perigosos à audição humana.

Os efeitos dos ruídos de impacto podem ser inócuos, como aplausos ou extremamente perigosos como explosões. Estes podem causar danos no aparelho auditivo, com rupturas mecânicas ou rompimento das estruturas sensoriais da orelha interna ${ }^{1}$.

O ruído de impacto decorrente de explosões pode causar mudanças fisiológicas ou anatômicas temporárias ou permanentes na cóclea, levando a distúrbios auditivos caracterizados por mudanças do limiar, dificuldades na percepção da fala e zumbidos ${ }^{2}$.

Quando o ouvido humano é exposto a um ruído de impulso, a uma intensidade sonora da ordem de $120 \mathrm{~dB}$ ou superior, ocorrerá o trauma acústico. A carga sonora produzirá, na cóclea, lesões intensas como ruptura da membrana basilar, desorganização dos tecidos e células ciliadas, de maneira abrupta. Clinicamente apresenta-se por perda auditiva neurossensorial imediata e permanente, uni ou bilateral, com a presença de zumbidos constantes. Em alguns casos, a perda auditiva pode apresentar alguma melhora após alguns dias, recuperando muitas vezes a audição social'5.

Nas explosões, podem ocorrer também lesões simultâneas da orelha média, como rotura do tímpano, desarticulação dos ossículos ou ainda lesão do sistema vestibular. Quando ocorre comprometimento da orelha média, há um mecanismo de proteção natural do órgão de Corti. Nesses casos, o comprometimento da orelha interna é menos intensa ${ }^{6}$.

No uso de arma de fogo, a energia acústica usualmente consiste em ruído de impulso, com picos de pressão sonora altos, entre 160 e $190 \mathrm{~dB}$, segundo Temmel et al. ${ }^{7}$. O súbito aumento da pressão acústica resulta em imediata e grave seqüela auditiva (perda auditiva profunda) como também de zumbidos. Muitos traumas acústicos ocorrem em serviços militares e indústria naval.

Segundo Stewart et al. ${ }^{8}$, nos Estados Unidos, os ruídos de explosão de arma de fogo são uma das primeiras causas de perda auditiva induzida por ruído. Com o aumento dos esportes de tiro, um número maior de pessoas vem sofrendo de trauma acústico ou perda auditiva neurossensorial gradual secundária a ruídos excessivos de arma de fogo. A perda auditiva repentina resulta da pressão sonora elevada do ruído de impulso que excede o nível crítico, podendo causar lesões, mecânicas ou metabólicas, nas estruturas da orelha interna. Já a perda auditiva gradual é resultado de exposição durante anos aos ruídos de impulso de arma de fogo que não são suficientemente altos para causar o trauma acústico, mas têm efeitos danosos, em longo prazo, às estruturas da orelha interna. Alguns pacientes procuram os serviços de audiologia devido à dificuldade no entendimento da fala $\mathrm{e}$ outros devido aos acúfenos.

No Brasil, Godoy $(1991)^{4}$ realizou um trabalho de avaliação auditiva no Curso de Formação de Militares do Exército, através de entrevistas e exames audiométricos dos alunos, no início e no final do curso. A autora detectou alterações na audição em um número significativo dos alunos (24\%) num intervalo de 20 meses. Essas alterações ocorreram predominantemente entre os indivíduos expostos a níveis de ruído superiores a $80 \mathrm{~dB}$.

Seballos (1995) realizou um estudo sobre a avaliação da condição auditiva em indivíduos expostos a ruído de arma de fogo, calibre 12. A intensidade sonora média à qual os indivíduos estavam expostos foi de $125,7 \mathrm{~dB}$. Detectou que a ocorrência de alteração auditiva causada por trauma acústico nos indivíduos expostos a ruído de arma de fogo é maior quando o tempo de exposição ao ruído for superior a 10 anos e nos indivíduos com idade avançada. No exame audiométrico detectou alteração significativa nas freqüências de 4 e $8 \mathrm{KHz}$.

Neves-Pinto et al. (1997) ${ }^{10}$ divulgaram, em 1963, suas observações sobre o trauma sonoro entre 60 militares da artilharia do exército, encontrando 23 casos de trauma sonoro típico. Estes mesmos autores realizaram vários outros trabalhos em aeronavegantes, encontrando alterações significativas na audição dos indivíduos pesquisados.

Brito $(1998)^{11}$ realizou um trabalho de avaliação auditiva em aeronavegantes civis e militares da Aeronáutica, para detectar as perdas auditivas precocemente. Os indivíduos submeteram-se a exames audiométricos convencionais e de 
altas freqüências (12 Kz). Os resultados acusaram alterações na freqüência de $12.000 \mathrm{~Hz}$ em indivíduos que eram considerados normais, no exame convencional, possibilitando detectar precocemente os problemas cocleares por exposição ao ruído.

Bandeira (1979) ${ }^{12}$ realizou um estudo sobre a avaliação auditiva de 54 militares que trabalham no serviço de segurança, realizando exercícios de tiros semanais. Detectou elevada incidência de disacusia neurossensorial (63,4\%), dos quais $30,7 \%$ apresentaram uma curva típica de trauma acústico.

Na Legislação Brasileira, relativa à segurança e medicina do trabalho, a Norma Regulamentadora $n^{\circ} 15$ (1978), estabelece limites de tolerância para o ruído contínuo ou intermitente e de impacto, respectivamente. No Anexo II são estabelecidos limites de tolerância para ruídos de impacto. Oferece risco grave e iminente a exposição, sem proteção, a níveis de ruído de impacto superiores a $140 \mathrm{~dB}$ (linear), medidas no circuito de respostas para impacto, ou superiores a $130 \mathrm{~dB}(\mathrm{C})$, medidas no circuito de resposta rápida $(\text { FAST) })^{3}$.

A presente pesquisa tem por objetivo avaliar os perfis auditivos de um grupo de militares de uma unidade do Exército e, em face dos resultados, incentivar a implementação de medidas preventivas para perdas auditivas, como o programa de conservação auditiva.

\section{MATERIAL E MÉTODO}

Trata-se de um estudo clínico transversal.

Projeto aprovado pela Comissão Nacional de Ética em Pesquisa (CONEP).

Foram examinados 97 sujeitos que trabalham em uma instituição militar do Exército, todos do sexo masculino, com idades variadas e que se expõem a locais de níveis de pressão sonora elevados.

A média de idade foi de 31,91 anos, variando entre 21 e 45 anos. Na distribuição por tempo de serviço a média foi de 12,75 anos, variando entre dois e 32 anos. Na análise de suas funções, foram divididos em três grupos: artilharia, administração e apoio (este inclui militares das áreas de: comunicação, saúde, manutenção e alimentação).

As avaliações auditivas consistiram de entrevistas, exame otorrinolaringológico e exames audiométricos. $\mathrm{Na}$ entrevista, foram pesquisados: a audição atual, o passado otológico, as doenças atuais e pregressas, antecedentes cirúrgicos e traumáticos, uso de medicamentos ototóxicos, exposição a ruídos anteriores ocupacionais e extraocupacionais, uso de armamentos, além de dados pessoais.

Realizou-se o exame otorrinolaringológico básico e a seguir, o exame audiométrico: os limiares tonais, limiares de reconhecimento da fala (SRT) e impedanciometria, com todos os sujeitos em repouso auditivo de 14 horas. Foram utilizados cabina acústica (Vibrasom VSA40), audiômetro
(Siemens SD25) e impedanciômetro (Dicton ZA44).

\section{RESULTADOS}

Dos 97 militares avaliados, $61,9 \%$ apresentaram traçados audiométricos dentro dos limites aceitáveis (limiares iguais ou melhores que $25 \mathrm{~dB}$ em todas as freqüências, de acordo com a Portaria 19 do Ministério do Trabalho e Emprego) (NR 7) ${ }^{13}$ e $38,1 \%$, traçados audiométricos alterados, a maioria sugestiva da perda auditiva induzida pelo ruído (Figuras 1 e 2).

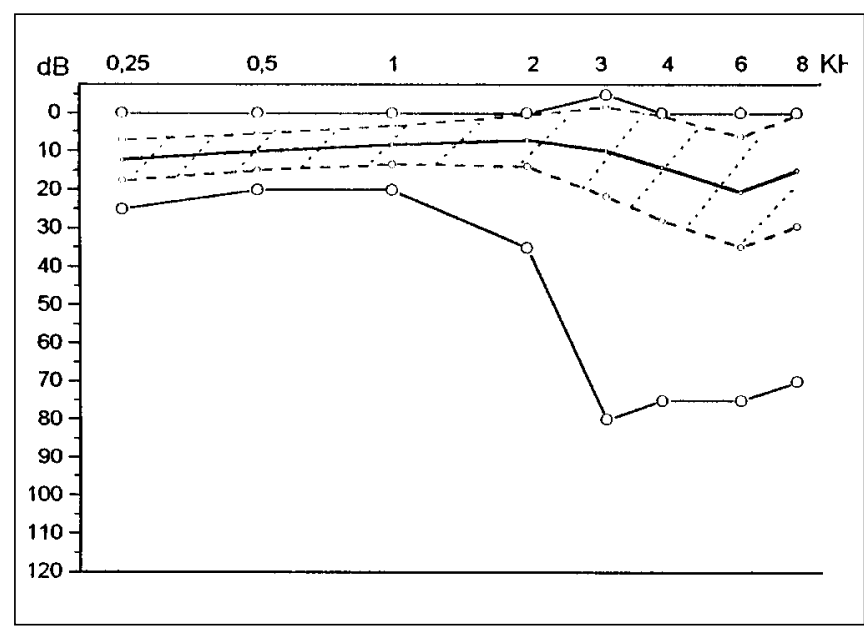

Figura 1. Gráfico das audiometrias dos militares, orelha direita. As linhas contínuas representam os valores médios, mínimos, máximos e as interrompidas os desvios padrão.

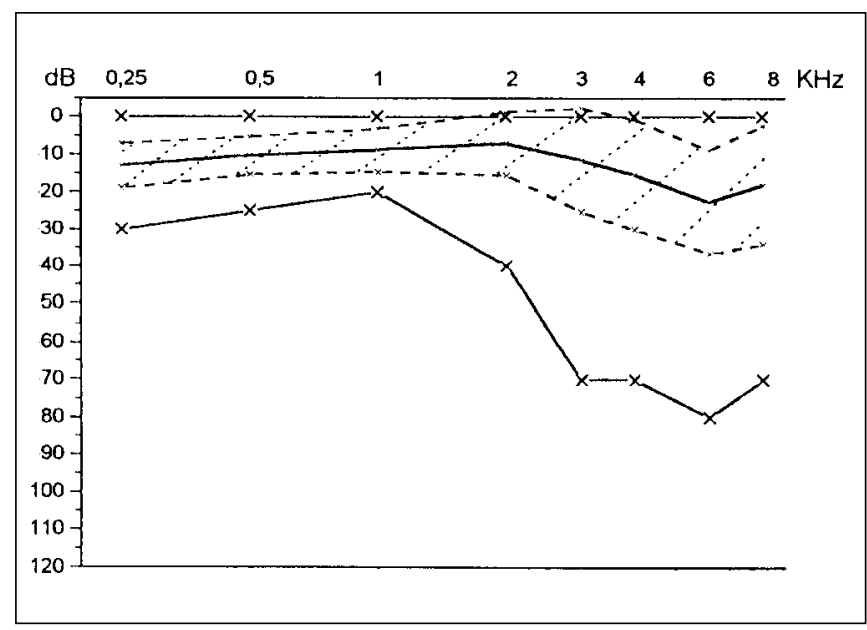

Figura 2. Gráfico das audiometrias dos militares, orelha esquerda As linhas contínuas representam os valores médios, mínimos, máximos e as interrompidas os desvios padrão. 
Na distribuição por faixa etária, a de 40 a 45 anos foi que apresentou maior percentual (60,0\%) de exames audiométricos alterados, a tendência foi de quanto maior a idade, maior o número de exames audiométricos alterados (Tabela 1).

$\mathrm{Na}$ distribuição por tempo de serviço, a faixa maior de 15 anos foi a que apresentou o maior percentual (46,1\%) de exames audiométricos alterados, a tendência foi de quanto maior o tempo de serviço, maior o número de exames audiométricos alterados (Tabela 2).

$\mathrm{Na}$ análise das funções exercidas pelos militares, a que apresentou maior percentual (42,9\%) de exames audiométricos alterados foi a da artilharia (Tabela 3).

Tabela 1. Distribuição por faixa etária e exames audiométricos alterados e dentro dos limites aceitáveis.

\begin{tabular}{cccc}
\hline Faixas de idades & № (\%) & \multicolumn{2}{c}{ Audiometria } \\
(21 a 45 anos) & & Alteradas & Normais \\
\hline $20^{-}-25$ anos & $14(14,5 \%)$ & $3(21,5 \%)$ & $11(78,5 \%)$ \\
$>25-30$ anos & $25(25,8 \%)$ & $10(40,0 \%)$ & $15(60,0 \%)$ \\
$>30-35$ anos & $36(37,1 \%)$ & $12(33,3 \%)$ & $24(66,7 \%)$ \\
$>35-40$ anos & $12(12,3 \%)$ & $6(50,0 \%)$ & $6(50,0 \%)$ \\
$>40-45$ anos & $10(10,3 \%)$ & $6(60,0 \%)$ & $4(40,0 \%)$ \\
\hline Totais & $97(100 \%)$ & $37(38,1 \%)$ & $60(61,9 \%)$ \\
\hline$(p=0,3099)$. & & &
\end{tabular}

Tabela 3. Distribuição por função exercida e exames audiométricos alterados e dentro dos limites aceitáveis.

\begin{tabular}{cccc}
\hline Função & № (\%) & \multicolumn{2}{c}{ Audiometria } \\
& & Alteradas & Normais \\
\hline Artilharia & $21(21,7 \%)$ & $9(42,9 \%)$ & $12(57,1 \%)$ \\
Administrativo & $33(34,0 \%)$ & $11(33,3 \%)$ & $22(66,7 \%)$ \\
Apoio & $43(44,3 \%)$ & $17(39,5 \%)$ & $26(60,5 \%)$ \\
\hline$(p=0,7571)$ & &
\end{tabular}

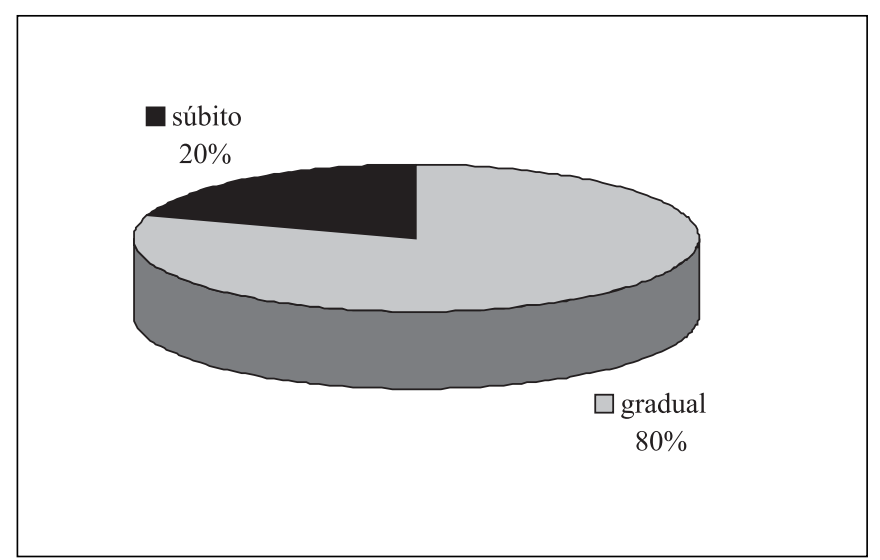

Gráfico 1. Modo relatado de instalação de perda auditiva $(n=25)$
Quanto à audição atual pesquisada na entrevista, 74,2 \% relataram sua audição atual como boa, enquanto 25,8\% relataram redução de grau médio. Dentre os indivíduos que relataram audição atual como boa, 30,5\% apresentaram audiometria alteradas (Tabela 4).

Dos que acusaram ter redução da audição de grau médio, 80\% relataram que a perda auditiva foi de início gradual (Gráfico 1) e 56\% não relacionam a perda auditiva com uma causa aparente (Gráfico 2).

Os sintomas mais relatados na entrevista foram irritação aos sons intensos e perda auditiva temporária (TTS) dentre outros listados na Tabela 5.

Tabela 2. Distribuição por tempo de serviço e exames audiométricos alterados e dentro dos limites aceitáveis.

\begin{tabular}{cccc}
\hline Tempo de Serviço & № (\%) & \multicolumn{2}{c}{ Audiometria } \\
(2 a 32 anos) & & Alteradas & Normais \\
\hline $0-5$ anos & $12(12,3 \%)$ & $1(8,3 \%)$ & $11(91,7 \%)$ \\
$5-10$ anos & $20(20,7 \%)$ & $8(40,0 \%)$ & $12(60,0 \%)$ \\
$10-15$ anos & $39(40,2 \%)$ & $16(41,0 \%)$ & $23(59,0 \%)$ \\
$>15$ anos & $26(26,8 \%)$ & $12(46,1 \%)$ & $14(53,9 \%)$ \\
\hline$(p=0,1452)$ & & &
\end{tabular}

Tabela 4. Correlação entre audição atual e audiometrias alteradas

\begin{tabular}{cccc}
\hline Audição Atual: & Números (\%): & \multicolumn{2}{c}{ Audiometria } \\
& & Alteradas & Normais \\
\hline Boa & $72(74,2 \%)$ & $22(30,5 \%)$ & $50(69,5 \%)$ \\
Média & $25(25,8 \%)$ & $15(60,0 \%)$ & $10(40,0 \%)$ \\
Ruim & $0(0 \%)$ & $0(\%)$ & $0(\%)$ \\
\hline Total & $97(100 \%)$ & $37(38,1 \%)$ & $60(61,9 \%)$ \\
\hline$(p=0,0090)$ & & &
\end{tabular}

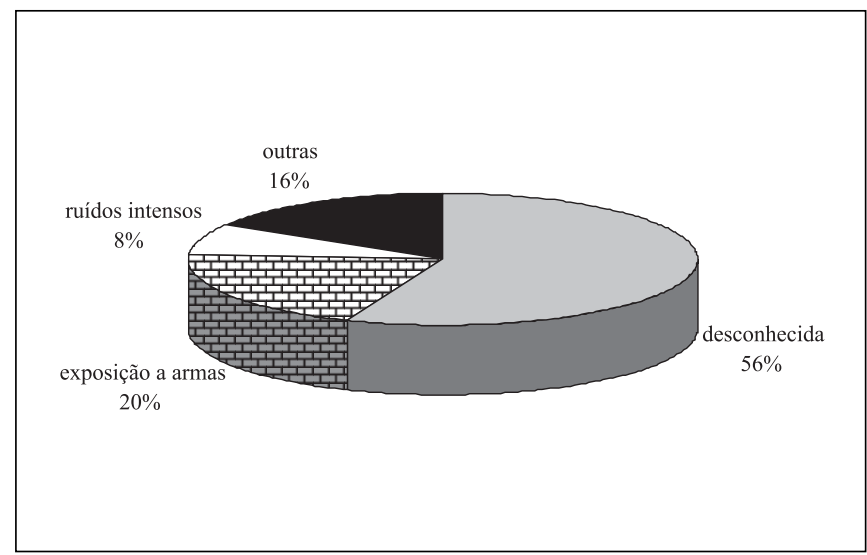

Gráfico 2. Causas relatadas para explicar a perda auditiva $(n=25)$ 
Tabela 5. Relação dos sintomas relatados na entrevista.

\begin{tabular}{lcc}
\hline Sintomas & Sim (\%) & Não (\%) \\
\hline - irritação com sons intensos & $53(54,6 \%)$ & $44(45,4 \%)$ \\
- perda auditiva temporária & $39(40,2 \%)$ & $58(59,8 \%)$ \\
- tonturas & $24(24,7 \%)$ & $73(75,3 \%)$ \\
- acúfenos & $16(16,5 \%)$ & $81(83,5 \%)$ \\
- plenitude auricular & $12(12,3 \%)$ & $85(87,7 \%)$ \\
- otalgia & $7(7,2 \%)$ & $90(92,8 \%)$ \\
- dificuldade em localizar & $4(4,1 \%)$ & $93(95,9 \%)$ \\
$\quad$ fonte sonora & & \\
\end{tabular}

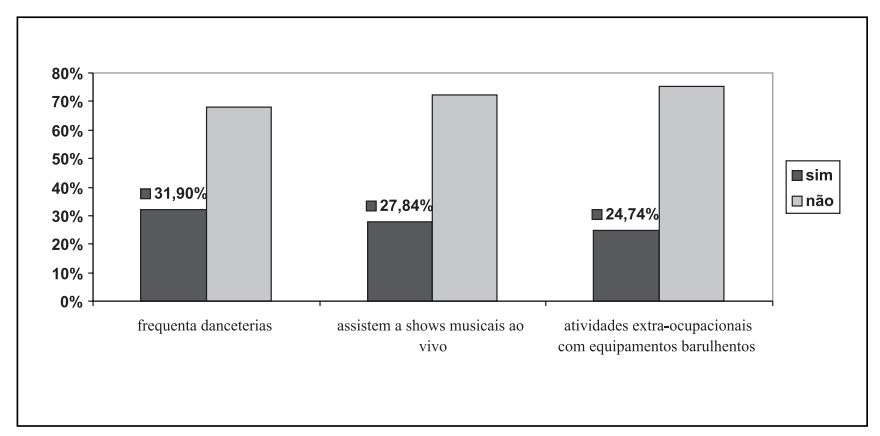

Gráfico 3. Exposição a ruído extra-ocupacional $(n=97)$

Tabela 6. Relaciona os tipos de armamentos e exposição ao ruído de impacto.

\begin{tabular}{lcc}
\hline TIPOS DE ARMAMENTOS & EXPOSTO & NÃO-EXPOSTO \\
\hline 1-fuzil automático leve & $88(90,7 \%)$ & $9(9,3 \%)$ \\
2-pistola 9mm & $94(96,9 \%)$ & $3(3,1 \%)$ \\
3-metralhadora de mão 9mm & $17(17,5 \%)$ & $80(82,5 \%)$ \\
4-metralhadora 50 m2 & $7(7,2 \%)$ & $90(92,8 \%)$ \\
5-obuseiro 155M & $37(38,1 \%)$ & $60(61,9 \%)$ \\
\hline
\end{tabular}

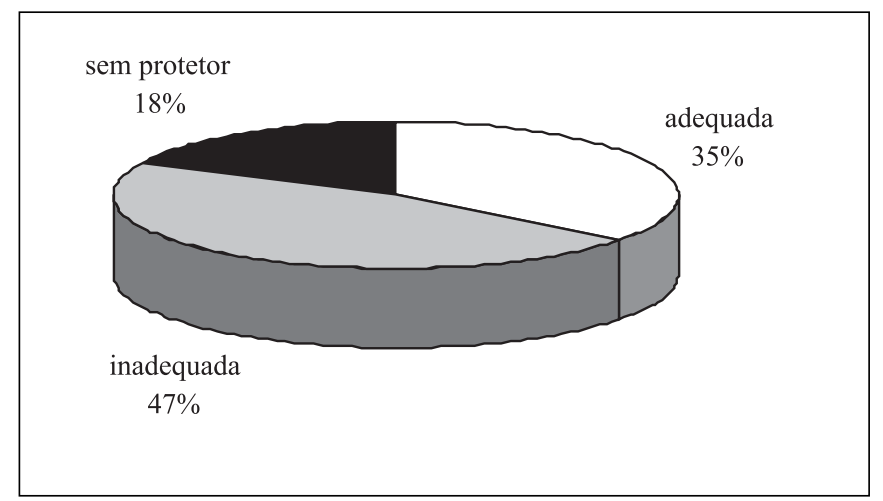

Gráfico 4. Relação da proteção auditiva usada nos exercícios de tiro.
Pesquisou-se, entre os militares, a exposição a ruído extra-ocupacional, sendo que as mais relatadas foram: freqüentar danceterias, assistirem a shows musicais ao vivo e realizar atividades com equipamentos barulhentos (Gráfico 3).

No trabalho atual, na instituição militar, 33,7\% relataram estarem expostos a ruído intenso, sendo que todos participam de exercícios de tiros com os diversos armamentos listados (Tabela 6).

82,3\% relatam uso de algum tipo de proteção auditiva durante a exposição ao ruído de arma de fogo, mas apenas $35,4 \%$ fazem uso de proteção adequada, como concha e plugue, $46,8 \%$ fazem o uso de proteção inadequada (algodão) e 17,7\% não fazem uso de proteção auditiva (Tabela 7 e Gráfico 4).

Quanto à perda auditiva unilateral foi encontrado uma maior porcentagem nas altas freqüências, sendo que a freqüência mais acometida foi a de $6 \mathrm{KHz}$ com 19,5\% (Tabela 8 e Gráfico 5). Com relação ao ouvido mais acometido o que apresentou uma maior porcentagem foi o ouvido esquerdo, nas freqüências acima de $2 \mathrm{KHz}$ (Tabela 9 e Gráfico 6).

\section{DISCUSSÃO}

Cox $\&$ Ford $^{14}$ constataram que 20 a 30\% dos militares têm perda de audição causada por exposição ao ruído de arma de fogo. No presente trabalho foi encontrado 38.14\% de perda auditiva nos sujeitos avaliados.

A faixa etária mais acometida foi dos 40 a 45 anos, e a tendência foi de quanto maior a idade, maior o número de exames audiométricos alterados. Estes resultados estão em concordância com o trabalho de Seballos', o qual detectou a ocorrência de alteração auditiva causada por trauma acústico nos indivíduos expostos a ruído de arma de fogo é maior nos indivíduos com idade mais avançada.

$\mathrm{Na}$ distribuição por tempo de serviço, os sujeitos com mais de 15 anos de exposição apresentaram o maior percentual de exames audiométricos alterados e a tendência foi de quanto maior o tempo de serviço, maior o número de exames audiométricos alterados, em concordância com o encontrado por Cox $\varepsilon$ Ford $^{14}$, no qual os indivíduos com mais de 15 anos de serviço militar a porcentagem da perda auditiva chega a mais de 50\%. Já nos estudos de Axelsson \& Hamernik $^{15}$ a perda auditiva máxima é alcançada com cinco anos de serviço militar, assim como no trabalho de Alvarez ${ }^{16}$ as alterações auditivas ocorreram quanto o tempo de exposição foi maior que seis anos.

Em relação à função dos sujeitos, o grupo mais acometido foi dos artilheiros, provavelmente por estarem expostos diretamente no campo nos exercícios de tiro com armamentos e obuseiro, desprotegidos ou protegidos inadequadamente. No estudo de Alvarez ${ }^{16}$ sobre incidência do trauma acústico em unidades de tanque e artilharia, o grupo 
mais afetado foi dos artilheiros, esta maior frequiência nos artilheiros foi atribuída à falta de meios de proteção auditiva.

Dos sujeitos entrevistados que relataram sua audição como boa, um terço apresentou audiometria alterada isso provavelmente ocorre, pois a maioria das perdas auditivas é encontrada nas freqüências altas. Alvarez ${ }^{16}$ explica que a hipoacusia foi pouco manifesta entre os indivíduos pesquisados, pois as freqüências acometidas estão entre $4 \mathrm{e}$ $8 \mathrm{kHz}$.

Dos sujeitos que relataram redução da audição em grau médio, $40 \%$ apresentaram audiometria dentro dos limites aceitáveis. Destes apenas 20\% relataram que a perda auditiva foi de início súbito, relacionado com exposição à arma de fogo e a ruídos intensos. A maioria relatou que a perda auditiva foi de início gradual, não relacionando com nenhuma causa. Em concordância com o trabalho de Stewart et al. ${ }^{8}$ a maioria dos pacientes expostos a ruídos excessivos de arma de fogo vem sofrendo tanto de trauma acústico quanto de perda auditiva neurossensorial gradual.

A maioria dos sujeitos (56\%) desconhece a causa da perda auditiva, não relacionando a nenhuma causa aparente.

A queixa mais freqüente, na presente amostra, foi de irritação aos sons intensos, seguido da perda auditiva temporária (TTS) após ruídos intensos. Já no estudo de Alvarez ${ }^{16}$, os sintomas mais encontrados foram o esgotamento excessivo, cefaléia e acúfenos; já no trabalho de Stewart et al. ${ }^{8}$, os pacientes procuram os serviços de audiologia devido à dificuldade no entendimento da fala ou aos acúfenos. Os acúfenos são os sintomas mais encontrados em vários outros estudos, sendo que no presente estudo foi relatado em apenas 16,49\% dos sujeitos. Segundo Mrena et al. ${ }^{17}$, os acúfenos e perdas auditivas são os sintomas mais comuns de serem relatados após ruído intenso causador do trauma acústico. Os acúfenos podem desaparecer após algum tempo ou persistirem por um longo período, afetando a qualidade de vida da pessoa ${ }^{17}$.
Atualmente se sabe que vários tipos de ruídos de alta intensidade são capazes de causar perda auditiva. Por isso foi pesquisada a exposição extra-ocupacional, sendo que cerca de um terço dos sujeitos relataram freqüentar danceterias, assistirem a shows musicais ao vivo e fazerem serviços com equipamentos barulhentos sem uso de nenhum tipo de proteção auditiva.

Com relação aos tipos de armamentos, mais de 90\% dos entrevistados estão expostos a ruídos de impacto de fuzil automático leve e pistola $9 \mathrm{~mm}$ e um terço se expõe ao ruído de obuseiro.

Apesar de terem conhecimento de que ruídos contínuos e de impacto de alta intensidade são causadores de lesões irreversíveis na orelha interna e que sua prevenção ocorre mediante a proteção auditiva, a maioria dos sujeitos entrevistados não é protegido adequadamente: $17,71 \%$ não usam nenhum tipo de proteção e 46,88\% usam apenas algodão, como proteção auditiva. Konopka et al..$^{18}$ estudaram dez soldados de 20 anos de idade, expostos a ruído de impacto de arma de fogo automática, sem proteção auditiva e detectou alterações na audição destes sujeitos. Temmel et al. ${ }^{7}$ realizaram um estudo sobre o trauma acústico causado por ruídos de impacto, em recrutas militares; $80 \%$ relataram não estar usando seus protetores quando o trauma acústico ocorreu. Nos casos de tiros ou explosões acidentais é esperado o não uso de protetores auditivos.

No presente trabalho as freqüências mais acometidas nos exames audiométricos foram entre 4 a $8 \mathrm{KHz}$, as mesmas encontradas no trabalho de Seballos e de Alvarez ${ }^{16}$. Já no estudo de Temmel et al. ${ }^{7}$ sobre trauma acústico, na análise da curva audiometria, $75 \%$ das perdas auditivas foram acima de $2 \mathrm{kHz}^{7}$.

Nesta pesquisa ocorreu um predomínio das perdas auditivas unilaterais sobre as bilaterais, sendo encontrado uma maior porcentagem nas freqüências altas. Temmel et al. ${ }^{7}$ realizaram um estudo sobre trauma acústico, e detectaram

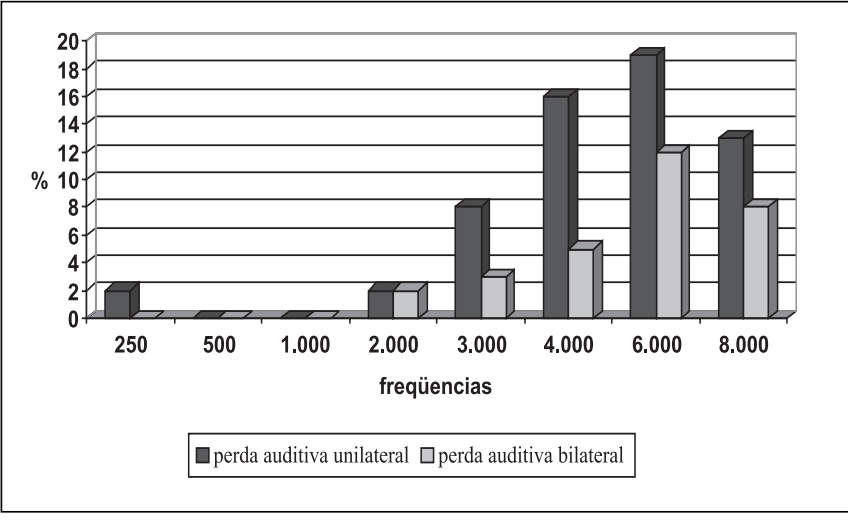

Gráfico 5. Relaciona a freqüência da perda auditiva uni e bilateral $(\mathrm{N}=37)$.

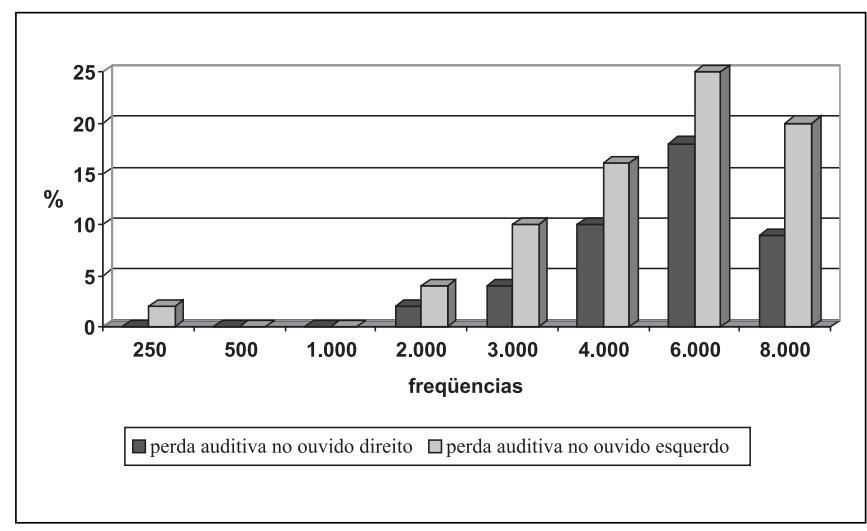

Gráfico 6. Relaciona a perda auditiva no ouvido direito e esquerdo $(\mathrm{N}=37)$. 
predomínio da perda auditiva unilateral $(80,2 \%)$ sobre a bilateral (13,6\%).

Com relação ao ouvido mais acometido, no presente trabalho, o ouvido esquerdo apresentou uma maior porcentagem em relação ao ouvido direito, nas freqüências acima de $2 \mathrm{KHz}$. No estudo de Alvarez ${ }^{16}$, a orelha esquerda também foi a mais afetada nos artilheiros. O autor acredita que a lesão depende da orelha que se encontra mais perto da fonte sonora (dadas às posições que ocupam cada um deles nos seus meios de combate).

Os autores observaram na entrevista que os sujeitos entrevistados não tinham nenhuma informação sobre os riscos auditivos causados pelo ruído de impacto dos armamentos utilizados, nem a maneira pela qual devem se proteger para evitar a perda auditiva. Por isso a necessidade de se implantarem medidas preventivas em unidades militares.

\section{CONCLUSÃO}

1. Dos 97 militares incluídos no estudo, expostos a ruído intenso em exercícios de tiros, 38,1\% apresentaram quadro otológico sugestivo de perda auditiva induzida por ruído.

2. Apenas $25,8 \%$ dos sujeitos que tinham queixas de perda auditiva e, dentre os não queixosos, $30,5 \%$ apresentaram alterações audiométricas características.

3. A perda auditiva encontrada foi mais intensa quanto maior a idade e o tempo de serviço.

4. As principais queixas observadas foram: irritação com sons intensos $(54,6 \%)$ e perda auditiva temporária $(40,2 \%)$. Os queixosos de acúfenos foram apenas 16,4\%.

5. Dos militares examinados, $64,59 \%$ não utilizaram proteção adequada nos exercícios de tiro.

6. Essa categoria profissional necessita de mais informação e de medidas preventivas para perda auditiva ocupacional.

\section{AGRADECIMENTOS}

Os autores agradecem ao Comandante da organização militar pela permissão e disponibilização da instituição para o desenvolvimento das entrevistas e exames realizados; e a todos os militares que participaram dessa pesquisa pela disponibilidade e colaboração.

\section{REFERÊNCIAS BIBLIOGRÁFICAS}

1. Patterson Jr JH, Johnson DL. Protection of hearing against highintensity impulse noise. J Acoust Soc Am 1996; 99(1):23.

2. Plontke SKR, Pfeffer C, Zenner HP, Dietz K. The incidence of acoustic trauma due to New Year's firecrackers. Eur Arch Otorhinlaryngol 2002; 259(5):247-52.

3. Brasil. Portaria no 3214. Ministério do Trabalho 08/07/1978/ NR15. Atividades e operações insalubres (D.O.U. 06/07/1978).

4. Godoy TCM. Perdas auditivas induzidas pelo ruído em militares: um enfoque preventivo; 1991.Tese de mestrado, PUC, São Paulo; 1991;1-136.

5. Bento RF, Miniti A, Marone SAM. Tratado de otologia.São Paulo, Editora USP: $1998 ; 274-82$

6. Hungria H. Trauma sonoro. Otorrinolaringologia. $7^{\mathrm{a}} \mathrm{ed}$, Rio de Janeiro: Ed. Guanabara Koogan: 1995; 389-92.

7. Temmel AFP, Kierner AC, Steurer M, Riedl S, Innitzer J. Hearing loss and tinnitus in acute acoustic trauma. Wien Klin Wochenschr 1999; 111(21):891-3.

8. Stewart M, Pankiw R, Lehman ME, Simpson TH. Hearing loss and hearing handicap in users of recreational firearms. J Am Acad Audiol_2002; 13(3):160-8.

9. Seballos SL. Condição auditiva de praticantes com arma de fogo; 1995. Tese de mestrado, Universidade Federal de Santa Maria, Rio Grande do Sul; 1995. p.1-64.

10. Neves-Pinto RMN, Monteiro ARC, Selimam J. Perda auditiva induzida pelo ruído: revisão das Publicações por Brasileiros no período 1938-1970. In: Nudelman AA, Costa EA, Seligman J Ibañez RN. PAIR - Perda auditiva Induzida pelo Ruído, Porto Alegre: Bagaggem Comunicação, 1997; 33-9.

11. Brito NAL Limiares auditivos na freqüência de $12.000 \mathrm{~Hz}$ em Aeronavegantes. Rev méd Aeronaut Bras 1998; 48(1/2):65-7.

12. Bandeira FAS, Fróes HC, Hercos Jr C. Trauma acústico. Rev Bras Otorrinol 1979; 45:261-6.

13. Brasil. Portaria no 19. Secretaria Segurança e Saúde no Trabalho 09/04/1998/ NR7. Programa de Controle médico de Saúde ocupacional. Anexo1. Diretrizes e parâmetros mínimos para avaliação e acompanhamento da audição em trabalhadores expostos a níveis de pressão sonora elevado. (D.O.U. 22/04/1998).

14. Cox HJ, Ford GR. Hearing loss associated with weapons noise exposure: when to investigate an asymmetrical loss. J Laryngol Otol 1995; 109:291-5.

15. Axelsson A, Hamernik RP. Acute acoustic trauma. Acta Otolaryngol 1987; 104:225-33.

16. Santana Alvarez J. Estúdio del trauma acústico em unidades de tanques y artilleria. Arch med Camagüey 1998; 2(3):6-12.

17. Mrena R, Savolainen S, Kuokkanen JT, Ylikoski J. Characteristics of tinnitus induced by acute acoustic trauma: a long-term followup. Audiol Neurootol 2002; 7(2):122-30.

18. Konopka W, Pietkiewicz P, Zalewski P. Otoacoustic emissions examinations in soldiers before and after shooting. Otolaryngol Pol 2002: 54(6):745-9. 